\title{
NILAI MORAL DALAM NOVEL KERLIP SANG BINTANG YANG HILANG KARYA ANNA AZLINA
}

\author{
Resti $^{1}$ Yunus $^{2}$ Marwati $^{3}$ \\ pbsi.fkip.uho@gmail.com
}

\author{
1,2,3, Jurusan Pendidikan Bahasa dan Sastra Indonesia, \\ Fakultas Keguruan dan Ilmu Pendidikan, Universitas Halu Oleo \\ Kampus Hijau Bumi Tridharma Anduonohu, Kendari, Indonesia
}

\begin{abstract}
Abstrak
Penelitian ini menelaah nilai moral dalam novel Kerlip Sang Bintang yang Hilang karya Anna Azlina. Karya sastra merupakan hasil cipta masyarakat atau sastrawan yang lahir dari fenomena yang ada dalam kehidupan masyarakat, sehingga dengan membaca dan memahami karya sastra berarti membaca dan memahami fenomena kehidupan. Berbagai fenomena kehidupan tersebut dituangkan dalam bentuk karya sastra sesuai konsep, pandangan, kemampuan, da kreativitas pengarang meramu realitas kehidupan ke dalam suatu bentuk karya imajinatif yang mampu memberi kenikmatan dan manfaat bagi kehidupan manusia. Rumusan masalah dalam penelitian ini adalah: bagaimanakah nilai moral yang terdapat dalam novel Kerlip Sang Bintang Yang Hilang karya Anna Azlina?. Tujuan penelitian ini adalah mendeskripsikan dan menganalisis nilai moral yang terdapat dalam novel Kerlip Sang Bintang Yang Hilang karya Anna Azlina. Penelitian ini merupakan penelitian deskripstif kualitatif. Sumber data yang digunakan dalam penelitian ini adalah novel Kerlip Sang Bintang yang Hilang karya Anna Azlina. Teknik pengumpulan data menggunakan teknik baca catat. Teknik analisis moral menggunakan pendekatan moral. Hasil analisis menunjukkan nilai moral dalam hubungan manusia dengan diri sendiri terdiri atas; rasa takut, rasa rindu dan kewajiban terhadap diri sendiri. Nilai moral hubungan manusia dengan manusia lain dalam lingkup sosial terdiri atas; menolong sesama, membantu yang lemah tanpa pamrih, cinta kasih sejati, dan saling menghargai. sedangkan nilai moral dalam hubungan manusia dengan Tuhan terdiri atas; pasrah menurut kepada Tuhan dan bersyukur kepada Tuhan. Dapat dijadikan sebagai bahan yang luas dan memiliki sikap positif terhadap karya sastra secara umum dan novel secara khusus serta dapat membantu siswa dalam memahami lebih mendalam tentang nilai moral yang baik dan buruk.
\end{abstract}

Kata kunci: nilai moral; novel; pendekatan moral 


\begin{abstract}
This research examines the moral values in Anna Azlina's novel Kerlip Sang Bintang yang Hilang. Literary works are the creation of people or writers who are born from existing phenomena in people's lives, so that reading and understanding literary works means reading and understanding the phenomena of life. These various life phenomena are manifested in the form of literary works according to the author's concepts, views, abilities, and creativity to mix the realities of life into an imaginative work that is able to provide enjoyment and benefits to human life. The formulation of the problem in this research is: what are the moral values contained in Anna Azlina's novel Kerlip Sang Bintang Yang Hilang ?. The purpose of this study is to describe and analyze the moral values contained in Anna Azlina's novel Kerlip Sang Bintang Yang Hilang. This research is a qualitative descriptive study. The data source used in this research is Anna Azlina's novel Kerlip Sang Bintang yang Hilang. The data collection technique used the reading note technique. Moral analysis techniques use a moral approach. The results of the analysis show that the moral values in human relations with oneself consist of; fear, longing and duty towards oneself. The moral values of human relationships with other humans in the social sphere consist of; helping others, helping the weak selflessly, true love, and mutual respect. while the moral values in the relationship between man and God consist of; surrender to obey God and give thanks to God. It can be used as a broad material and has a positive attitude towards literature in general and novels in particular and can help students understand more deeply about good and bad moral values.
\end{abstract}

Key words: moral values; novel; moral approach 


\section{PENDAHULUAN}

Karya Sastra merupakan Hasil kreativitas manusia sebagai cerminan kehidupan manusia. Hal tersebut terlihat dari permasalahan yang dituangkan di dalam karya sastra juga sering terjadi di dunia nyata atau sebaliknya. Akan tetapi karena karya sastra merupakan hasil kreatif manusia jadi tidak semata-mata karya sastra tersebut merupakan duplikasi dari kehidupan nyata, melainkan ada unsur kreatif didalamnya berlandaskan permasalahan yang ada di dunia nyata. Karya sastra juga dapat di katakan sebagai penciptaan kembali oleh pengarang dari suatu permasalahan yang nyata dengan bahasa sebagai media penyimpanannya. Sebagai seni yang lahir dari hasil kreatif manusia, karya sastra tidak hanya sebagai media untuk menyampaikan gagasan, teori, ide atau sistem pemikiran manusia, akan tetapi harus mampu menciptakan kreasiyang indah dan menyenangkan.

sekitarnya.

Sebagai sebuah karya imajinatif, fiksi menawarkan berbagai permasalahan manusia dan kemanusiaan, hidup dan kehidupan. Pengarang menghayati berbagai permasalahan tersebut dengan penuh kesungguhan yang kemudian diungkapkan kembali melalui sarana fiksi sesuai dengan pandangannya. Oleh karena itu, fiksi, menurut Altenbernd dan Lewis (dalam buku Nurgiyantoro, 2013: 3), dapat diartikan sebagai "prosa naratif yang bersifat imajinatif, namun biasanya masuk akal dan mengandung kebenaran yang mendramatisasikan hubungan-hubungan antar manusia. Pengarang mengemukakan hal itu berdasarkan pengalaman dan pengamatannya terhadap kehidupan. Namun, hal itu dilakukan secara selektif dan dibentuk sesuai dengan tujuannya yang sekaligus memasukkan unsur hiburan dan penerangan terhadap pengalaman kehidupan manusia". Fiksi menceritakan berbagai masalah kehidupan manusia dalam interaksinya dengan lingkungan dan sesama, interaksinya dengan diri sendiri, serta interaksinya dengan Tuhan. Pada dasarnya, prosa fiksi merupakan karya imajinatif yang dilandasi kesadaran dan tanggung jawab dari segi kreativitas sebagai karya seni. Oleh karena itu, fiksi merupakan sebuah cerita yang di dalamnya terkandung tujuan untuk memberikan hiburan kepada pembaca di samping adanya

Sastra merupakan salah satu sarana untuk mengungkapkan masalah manusia dan kemanusiaan. Sastra merupakan hasil cipta kreatif dari seseorang pengarang yang lahir melalui proses perenungan dan penggambaran yang lahirsebuah realitas kehidupan masyarakat. Melalui karya sastra, pengarang berusaha untuk mengungkapkan nilai-nilai kemanusiaan yang lebih tinggi. Pengarang adalah bagian dari masyarakat menangkap realitas dari nilai-nilai masyarakatnya kemudian secara kreatif mengolah dan mengekspresikan dalam bentuk karya sastra.

(Sumardjo, 1995:7) Sebuah karya sastra juga harus memberikan kegembiraan, kesenangan, kepuasan, dan keindahan kepada pembacanya. Itulah cara untuk menyampaikan berbagai penemuan intelektual. Kadar temuan yang sama dapat saja tidak dikemukakan melalui cara sastra misalnya, secara ilmiah. Bentuk keindahan yang dipilih karya sastra hanyalah sekadar cara penyampaikan pesan. Karya sastra lahir karena adanya suatu yang menjadikan jiwa seorang pengarang atau pencipta mempunyai rasa tertentu pada suatu persoalan atau peristiwa di dunia ini, baik yang langsung dialaminya maupun dari kenyataan hidup sehari-hari yang ada di masyarakat(Wicaksono, 2014: 4).

Nilai moral dalam karya sastra biasanya mencerminkan pandangan hidup pengarang yang bersangkutan, pandangan tentang nilainilai kebenaran, dan hal itulah ingin disampaikan kepada pembaca. Moral dalam cerita, menurut Kenny (dalam Nurgiyantoro, 2015: 430), biasanya dimaksudkan sebagai suatu saran yang berhubungan dengan ajaran moral tertentu yang bersifat praktis, yang dapat diambil (dan ditafsirkan) lewat cerita yang bersangkutan oleh pembaca. Nilai moral yang terkandung dalam sebuah novel sangat penting. Artinya, dalam sebuah karya sastra harus memasukkan nilai moral dalam karyanya. Nilai moral membahas tentang perbuatan, sikap, tanggung jawab dan kewajiban. Nilai moral dalam karya sastra sangat berpengaruh terhadap pembacanya,

\section{4 | Jurnal BASTRA (Bahasa dan Sastra), Vol. 5 No.1, Edisi Januari 2020/e-ISSN: 2503-3875/}

http://ojs.uho.ac.id/index.php/BASTRA 
Karena nilai moral merupakan sesuatu yang baik, yang baik atau bermoral itu bukanlah masalah tetapi jauh dari nilai moral, maka akan sangat buruk akibatnya. Moral dalam karya sastra biasanya mencerminkan pandangan hidup pengarang yang bersangkutan, pandangan tentang nilai-nilai kebenaran dan hal itulah yang ingin disampaikan kepada pembaca.

Novel Kerlip Sang Bintang Yang Hilang karya Anna Azlina merupakan novel yang kaya penuh hikmah dan nilai-nilai moral. Nilai moral yang terdapat dalam novel Kerlip Sang Bintang Yang Hilang karya Anna Azlina terkesan dalam keseluruhan cerita teraktualisasikan melalui unsur pembangun karya sastra. Novel Kerlip Sang Bintang Yang Hilang karya Anna Azlina sangat menarik untuk di teliti karenan menceritakan tokoh Kerlip dan Bintang. Jalinan persahabatan dua anak jalanan, bermulai kala Bintang menyelamatkan Kerlip yang di kejar-kerjar oleh preman di daerah Gilingan, Solo. Demi menyelamatkan kerlip yang di tuduh mencuri, Bintang dengan berani menghadapi komlpotan geng Brenos. Persahabatan mereka diuji saat tiba-tiba kerlip pergi dari LSM Seroja, tempat mereka tinggal setelah di tolong oleh Tina, yang peduli terhadap anak jalanan.

Alasan peneliti untuk menganalisis novel Kerlip Sang Bintang Yang Hilang Karya Anna Azlina yaitu karna novel tersebut sangat menarik untuk dikaji khususnya di tinjau dari nilai moral berdasarkan hubungan manusia dengan dirinya sendiri, hubungan manusia dengan manusia lain dalam lingkup sosial, serta hubungan manusia dengan tuhannya. Dalam berbagai problematika sosial dalam kehidupan anak jalanan. Serta novel ini sangat menarik untuk di teliti karena menceritakan tentang persahabatan dua orang anak jalanan. Arti penting kepedulian sesama, kejujuran, kerja keras, dan pantang menyerah. Selain itu dalam novel ini, memberikan aspirasi kepada pembaca bahwa keberhasilan adalah hak setiap orang yang mempunyai semangat dan kerja keras.
Berdasarkan uraian latar belakang di atas maka yang menjadi permasalahan dalam penelitian ini yaitu bagaimanakah nilai moral yang terdapat dalam novel Kerlip Sang Bintang Yang Hilang karya Anna Azlina?

Adapun tujuan penelitian ini adalah untuk mendeskripsikan dan menganalisis nilai moral yang terdapat dalam novel Kerlip Sang Bintang Yang Hilang karya Anna Azlina.

a. Pembaca sebagai penikmat sastra akan lebih memahami nilai moral yang terkandung dalam novel Kerlip Sang Bintang Yang Hilang karya Anna Azlina.

b. Pemberi motivasi atau masukan terhadap guru dan siswa dalam menganalisis atau mencari makna yang terkandung dalam sebuah karya sastra khususnya novel.

c. Sebagai bahan penelitian lanjutan dalam melakasanakan penelitian yang relevan dengan penelitian ini.

\section{METODE DAN TEKNIK PENELITIAN}

Jenis dan Metode Penelitian

Jenis penelitian ini dapat digolongkan ke dalam penelitian kepustakaan, yakni penelitian ini di dukung oleh referensi baik berupa teks novel maupun buku lainnya yang menunjang dan relevan penelitian ini.

Metode yang digunakan dalam penelitian ini adalah metode deskriptif kualitatif. Dikatakan deskriptif karena dalam penelitian ini mendeskripsikan data berdasarkan kenyataan-kenyataan secara objektif, sesuai dengan data yang ditemukan. Dikatakan kualitatif karena menjelaskan konsep-konsep yang berkaitan satu sama lain dilakukan menggunakan kata-kata atau kalimat, bukan menggunakan angka-angka statistik.

Data dan Sumber Data

Data dalam penelitian ini adalah data tertulis berupa teks novel yang berhubungan dengan nilai moral yang terdapat dalam novel Kerlip Sang Bintang yang Hilang karya Anna Azlina. Sumber data dalam pengkajian ini adalah novel Kerlip Sang Bintang yang Hilang karya Anna Azlina yang diterbitkan oleh DIVA Press cetakan pertama Agustus 2015 dan terdiri dari 236 halaman.

\section{5 | Jurnal BASTRA (Bahasa dan Sastra), Vol. 5 No.1, Edisi Januari 2020/e-ISSN: 2503-3875/}

http://ojs.uho.ac.id/index.php/BASTRA 
Teknik Pengumpulan Data

Teknik pengumpulan data yang digunakan dalam penelitian ini adalah teknik baca dan catat yang dilaksanakan dengan langkah-langkah sebagai berikut:

1. Peneliti mencari, mengumpulkan, membaca dan mempelajari sumber-sumber tertulis berupa buku, artikel, yang berkaitan dengan nilai moral untuk memperoleh data.

2. Peneliti menggunakan teknik pencatatan yaitu teknik yang digunakan untuk mencatat data yang diperoleh dari hasil membaca.

\section{Teknik Analisis Data}

Data penetilitan ini dianalisis berdasarkan pendekatan moral. Pendekatan ini merupakan suatu pendekatan yang penting, sebab pendekatan apapun yang dilakukan pada dasarnya bertumpu atas karya sastra itu sendiri. Analisis data dilakukan dengan langkah-langkah sebagai berikut:

a. Mengidentifikasi data yang berhubungan dengan nilai moral yang terdapat dalam novel Kerlip Sang Bintang yang Hilang karya Anna Azlina.

b. Klasifikasi, yaitu menghasilkan (mengelompokkan data) pesan berdasarkan jenis moralnya.

c. Analisis data, yaitu data yang menjadi objek dengan pendekatan moral.

d. Interpretasi data, yaitu memberikan gambaran secara umum tentang hasil penelitian yang diperoleh, hal tersebut tampak pada kesimpulan penelitian.

\section{HASIL DAN PEMBAHASAN}

2.1.1 Nilai Moral dalam Hubungan Manusia dengan Dirinya Sendiri

\subsubsection{Rasa Takut}

$>$ Bintang

"Tidak, Aku tidak mau mengemis! Bukankah Pak Ustadz pernah bilang, Allah membenci seorang hamba yang meminta-minta, sementara ia mampu berusaha?" (Azlina, 2015: 26)

Kutipan berikut jelas digambarkan bahwa ketakutan Bintang akan hukuman bagi perbuatan mengemis yang sangat dibenci oleh
Allah membuat ia tidak mau dan tidak ingin melalukan perbuatan tersebut. Karena dalam Islam sesungguhnya mengemis itu tidak halal dan menjelaskan bahwa tangan yang berada di atas (memberi) itu lebih mulia dibandingkan dengan tangan yang di bawah (menerimna). Ia mengetahui perbuatan itu tidak baik apalagi ia masih sehat dan bisa bekerja untuk menghidupi dirinya.

\subsubsection{Rasa Rindu}

\section{$>$ Bintang}

"Bintang Sendiri memang sangat merindukan Kerlip, karena banyak suka dan duka yang telah dialaminya bersama. Dimana kau, Kerlip?" (Azlina, 2015: 209-210)

Kutipan di atas menggambarkan kerinduan Bintang terhadap Kerlip yang tibatiba menghilang, karena mengingat perjuangan, persahabatan, kebersamaan mereka saat masih menjual lukisan dan menjual koran baik suka maupun duka mereka tetap bersama-sama. Rindu ini terjadi ketika seseorang rindu dengan kenangan masa lalu, kenangan dulu, atau merindukan angan-angan masa depan. Hal tersebut dapat dilihat dalam kutipan tersebut.

"Bintang berharap, buku ini bisa mepertemukannya dengan sahabatnya yang bernama Kerlip.” (Azlina, 2015: 209)

Kutipan tersebut menggambarkan Bintang sangat ingin bertemu dengan sahabat lamanya dulu yaitu Kerlip semenjak ia menghilang di LSM Seroja. Dengan menerbitkan buku ia berharap akan di pertemukan oleh kawan seperjuangannya. Bintang sangat berharap kedatangan Kerlip Karena dia sudah menganggap Kerlip seperti saudaranya sendiri.

\subsubsection{Kewajiban Terhadap Diri Sendiri}

$>$ Tina

"Tina hanya ingin mendapatkan uang hasil dari keringat sendiri, bukan karena Ayah ataupun Bunda." (Azlina, 2015: 76)

Dalam kutipan tersebut Tina tidak ingin bergantung kepada orang tuanya yang bergelimang harta, meskipun dia dari keluarga konglongmerat Tina bekerja sendiri dan

\section{6 | Jurnal BASTRA (Bahasa dan Sastra), Vol. 5 No.1, Edisi Januari 2020/e-ISSN: 2503-3875/}

http://ojs.uho.ac.id/index.php/BASTRA 
memilih perusahaan yang kualitasnya rendah dibawah perusahaan orang tuanya. Tina juga tidak lupa dengan kewajiban sendiri dan sesamanya. Baginya hidup berbagi, bersahaja, dan selalu mengenal tuhan itu jauh lebih menyenangkan dibandngkan dengan begunung-gunung uang yang ia nikmati selama ini.

\subsubsection{Nilai Moral dalam Hubungan Manusia dengan Manusia Lain dalam Lingkup Sosial \\ 2.1.2.1 Menolong Sesama \\ $>$ Kakek Ali \\ "Pakailah sepeda Kakek yang ada di rumah, Nak! Agar kalian tidak kecapekan." (Azlina, 2015: 58)}

Kutipan di atas menggambarkan Kakek Ali memiliki rasa peduli sesama dan orang lain, apalagi kepeduliannya dengan anak jalanan. Banyak hal yang dilakukan Kakek Ali agar kehidupan terasa lebih bermakna. Pada dasarnya Kakek Ali digambarkan sebagai mahluk sosial. Sekaya apapun seseorang, dia tetap saja hidup sendirian. Jangankan untuk hal-hal yang besar, untuk sesuatu yang sederhana saja dia tidak dapat berdiri. Dalam kutipan tersebut Kakek Ali menawarkan sepeda yang ada dirumah agar Kerlip dan Bintang tidak merasa capek, ia hanya ingin menolong karena menolong orang adalah kewajiban apalagi dalam membutuhkan bantuan.

\subsubsection{Membantu Yang Lemah \\ Tanpa Pamrih}

$>$ Tina

"Di saat semua orang sibuk berdebat, Tina memberanikan diri untuk meminta orang-orang yang berkerumun tersebut untuk memindahkan tubuh lali-laki yang tertembak itu ke dalam mobilnya. Mereka kemudian bergotong-royong mengangkat tubuh laki-laki tersebut dan menaruhnya kedalam mobil Tina yang terparkir di depan pasar." (Azlina, 2015: 79)

Kutipan di atas, menggambarkan bahwa Tina membantu orang yang lemah adalah kewajiban kita sesama manusia. Tanpa berpikir panjang meminta orang-orang berkerumun untuk memindahkan tubuh lelaki yang tertembak kedalam mobilnya. Karena setiap kehidupan tidak ada yang hidup tanpa orang lain.

\subsubsection{Cinta Kasih Sejati \\ $>$ Bunda \\ "Tina merasa kasih sayang yang diberikan oleh bunda sangat besar, bahkan teramat sayang sehingga teman-temannya sering meledeknya dengan sebutan, anak mami. Ketika Tina sibuk, Bunda sering membuatkan teh hangat dan dua potong kue diletakkan di meja kerja anak kesayangannya itu." (Azlina, 2015: 74) \\ Dalam kutipan diatas cinta kasih} sejati bukan hanya dalam sepasang kekasih atau dua sejoli saling menyayangi satu sama lain. cinta kasih sejati bisa digambarkan antara ibu dan anak. Ketika tina sedang sibuk dengan pekerjaan kantornya tidak lupa bunda menyuguhkan secangkir teh hangat dan dua potong kue kepada anak kesayanganya itu. Tina adalah anak semata wayang atau tunggal jadi Bunda sangat menyayanginya, bahkan teramat sayangnya sejak kecil teman-teman tina sering meledeknya dengan sebutan "anak mami".

\subsubsection{Saling Menghargai}

$>$ Tina

"Tina menghela nafas panjang. Ia tahu kalau Bintang sedang menyembunyikan sesutu, tapi ia tidak mau bertanya lagi. Ia tidak mau memojokkan Bintang dan ia juga menghargai sikap Bintang tersebut." (Azlina, 2015: 138)

dalam kutipan ini menjelaskan bahwa

Tina tidak ingin memaksa Bintang mengatakan apa yang ia sembunyikan karena Tina menyadari bahwa tidak semua hal harus ia ketahui tentang apa yang dirasakan oleh Bintang. Sikap saling menghargai terlihat jelas dalam kutipan tersebut.

\subsubsection{Nilai Moral dalam Hubungan Manusia dengan Tuhannya 2.1.3.1 Pasrah dan Menurut Kepada Tuhan}




\section{$>$ Kerlip}

"Ya! Aku Yakin Allah akan menolong hambanya yang tak bersalah." (Azlina, 2015: 105)

Dalam kutipan di atas menggambarkan Kerlip hanya bisa pasrah kepada Allah karena ia di tuduh mencuri dan di penjara. Dengan penuh keyakinan Allah akan membatu hambanya yang tidak bersalah. Karena sesungguhnya kita sebagai manusia adalah milik Allah dan hanya kembali kepadaNya.

\subsubsection{Bersyukur Kepada Tuhan \\ $>$ Tina \\ "Pemahaman menurut Tina semestinya membuat manusia bersujud kian rendah dalam syukur kepada allah." (Azlina, 2015: 166) \\ Dalam kutipan tersebut} menggambarkan bahwa Tina, Allah yang mengabulkan doa manusia boleh berencana tetapi hanya perkenaan-Nya semua terwujud. Rasa syukur kepada Tuhan dapat diwujudkan melalui tutur kata dan tindakan. Pada dasarnya bersyukur adalah berterima kasih. Bersyukur kepada tuhan berarti berterima kasih atas nikmat yang telah Tuhan berikan. Nimat yang dikaruniakan hakikat adalah cobaan. Boleh saja memilih untuk bersyukur atau tidak. Bersyukur secara batiniah memang tidak nampak. Rasa syukur kadang muncul seperti sebuah kelegaan di dalam hati tokoh tersebut.

\section{PENUTUP}

\section{Kesimpulan}

Dari hasil penelitian yang dilakukan terhadap novel Kerlip Sang Bintang Yang Hilang karya Anna Azlina, dapat disimpulkan bahwa novel tersebut banyak mengandung nilai moral yang sangat bermanfaat bagi pembaca. Nilai moral dalam hubungan manusia dengan dirinya sendiri, hubungan manusia dengan manusia lain dalam lingkup sosial dan hbungan manusia dengan Tuhan. Hal itu dilakukan atas kesadaran moral yang telah melekat dalam diri individu yang tidak mengharapkan imbalan maupun pujian.

Saran

Berdasarkan kesimpulan tersebut, maka peneliti menyarankan beberapa hal sebagai berikut. a. Perlu adanya peningkatan dalam penelitan sastra pada umumnya dan penelitan novel pada khususnya.

b. Hasil penelitian yang dilakukan terhadap novel Kerlip Sang Bintang yang Hilang karya Anna Azlina dengan judul nilai moral dapat dijadikan bahan pembelajaran di sekolah khususnya menganalisis unsur karya sastra.

c. Penelitan ini hanya mengkaji nilai moral yang terkandung dalam novel, untuk itu kepada peneliti sastra hendaknya melanjutkan menganalisis dengan aspek lain yang tentunya dalam novel tersebut.

d. Hasil penelitian ini dapat di jadikan sebagai bahan pembelajaran di sekolah agar siswa dapat memiliki pengetahuan yang luas dan memiliki sikap yang positif terhadap karya sastra secara umun dan novel secara khusus. Selain itu, hasil oenelitian ini dapat membantu siswa dalam memahami lebih mendalam tentang nilai moral yang baik dan buruk.

\section{DAFTAR PUSTAKA}

Jabrohim, 2014:Teori Penelitian Sastra. Yigyakarta. Pustaka Pelajar.

Luxemburg, Jan Van, dkk. 1966. Pengantar Ilmu Sastra. Jakarta. Gramedia.IKAPI.

Azlina, Anna, 2015. Kerlip Sang Bintang yang Hilang. Yogyakarta. Diva Press Anggota IKAPI.

Nurgiyantoro, Burhan. 2005. Sastra Anak. Yogyakarta. Gadjah Mada University Press Anggota IKAPI.

Nurgiyantoro, Burhan. 2010. Teori Pengkajian Fiksi. Yogyakarta. Gadjah mada University Press Anggota IKAPI.

Nurgiyantoro, Burhan. 2013. Teori Pengkajian Fiksi. Yogyakarta. Gadjah Mada University Press Anggota IKAPI.

Nurgiyantoro, Burhan. 2015. Teori Pengkajian Fiksi. Yogyakarta. Gadjah Mada University Press Anggota IKAPI.

Padi, Editorial. 2013. Kumpulan Super Lengkap Sastra Indonesia. Jakarta. CV. Ilmu Padi Infra Pustaka Makmur.

Semi, M. Atar, 1990. Metode Penelitian Sastra. Bandung. Angkasa.

Sumardjo, Jakob. 1995. Sastra Massa. Bandung. ITB

\section{8 | Jurnal BASTRA (Bahasa dan Sastra), Vol. 5 No.1, Edisi Januari 2020/e-ISSN: 2503-3875/}

http://ojs.uho.ac.id/index.php/BASTRA 
Sudjiman, Panuti. 1998. Memaknai Cerita Rekaan. Jakarta. Pustaka Jaya.

Tarigan, Hendry Guntur, 1995. Dasar-Dasar Psiko Sastra. Bandung. Angkasa.

Wicaksono, Andri, 2014 pengkajian Prosa Fiksi. Yogyakarta. Garudhawaca. 